\title{
The effect of unilateral vasectomy on testosterone and testicular parameters in the adult male African giant rat (Cricetomys gambianus)
}

\author{
Duru FIO ${ }^{1}$, Ajayi $\mathrm{S}^{1}, *$ Azu OO ${ }^{2}$
}

1. Department of Anatomy, College of Medicine, University of Lagos, Nigeria.

2. Discipline of Clinical Anatomy, Nelson R Mandela School of Medicine, University of KwaZulu-Natal, Private Bag X54001, Durban, South Africa.

\begin{abstract}
Background: The effects of vasectomy on spermatogenesis and reproductive parameters are recognized to be speciedependent with marked differences in levels of perturbations observed.

Objectives: To assess the impact of unilateral vasectomy on testosterone level and other testicular parameters in the male African giant rat (AGR) (Cricetomys gambianus).

Methods: Sixteen adult male AGRs weighing 500-1300 g were recruited for the experiment. Animals were randomly divided into three experimental groups (1-3) and one control (sham operated) group with four rats per group. Experimental vasectomy was done by carefully ligating the vas deferens of the right testis of all the experimental groups $(1,2$, and 3$)$ and animals were allowed either 8, 6 and 2 weeks respectively before sacrifice. Sham-operated animals served as the control. Blood samples were collected and assayed for testosterone while testicular tissue was further processed for seminal fluid and histo-pathological analyses.

Results: Spermatogenic parameters indicate a pattern of decline in sperm count and motility between the experimental groups and the control and azoospermia in the eight-week group. Histological alterations were marked by atrophy of seminiferous tubules which was proportional to the duration of vasectomy. Serum testosterone levels were significantly reduced at eight weeks. There was no statistically significant difference between sperm counts of right and left testes except for group 3. Results suggest that unilateral vasectomy of the AGR may have negative impact on the contralateral testis in the male African giant rat.
\end{abstract}

Conclusion: These preliminary results reveal that unilateral vasectomy in the AGR may result in perturbations of the histoarchitecture of the testes with possible decline in function.

Key words: African giant rat, vasectomy, testis.

African Health Sciences 2013; 13(2): 483 - 489 http://dx.doi.org/10.4314/ahs.v13i2.40

\section{Introduction}

Vasectomy which is the surgical ligation of the vas deferens has been in use as a popular method of contraception $^{1,2}$ for men. However, despite the controversies surrounding the applicability of vasectomy as a male contraceptive method ${ }^{3}$, it has continued to attract continued interest from researchers and urologists. The contraceptive effectiveness of this technique has been established by investigators but they continue to generate sharp divisions as to the potential deleterious consequences thereafter ${ }^{4}$.

\section{*Corresponding author: \\ Onyemaechi Okpara Azu \\ University of KwaZulu-Natal \\ Nelson R Mandela School of Medicine \\ Private Bag X54001 \\ Durban, South Africa \\ Email: amechi2@yahoo.com,azu@ukzn.ac.za}

The vas deferens, a tubular structure that carries sperm from the cauda epididymis to the ejaculatory duct, consists of three muscular layers and a mucosal inner layer ${ }^{5}$. This important structure has been a subject for manipulations specifically in respect to male contraception. It appears that injury to the vas deferens will impact negatively on fertility parameters in the male ${ }^{1}$ as this is supported by experiments showing increased seminiferous tubular diameters, obstruction of spermatogenesis and sperm maturation process ${ }^{6}$. Although evidence from studies in animals and humans suggest that vasectomy does not affect reproductive hormones, reports of spermatogenic damage indicated by sloughing of seminiferous epithelium ${ }^{8}$ have been observed. In the light of divergent views/reports by authors, our current knowledge of the alterations following vasectomy remains but incomplete and requires further investigation. Against this standpoint, 
factors like species/strain of animal, differences in experimental designs and parameters evaluated, technique of vasectomy applied and time interval after vasectomy may have contributed to the different views expressed by authors.

Since the rat is an animal model frequently used for the study of vasectomy ${ }^{4}$ and they continue to exist variability in data regarding outcome of this procedure on various parameters, the current pilot study was undertaken to observe how the African giant rat (AGR) (Cricetomys gambianus) responds to vasectomy procedure. The AGR is known to be wild and nocturnal species which is gradually becoming domesticated for various purposes and the anatomy is attracting intense interest ${ }^{9}$; hence knowledge of how it responds in this experimental study would stimulate a more detailed investigation that would add to the comparative data with other species/ strain.

There is paucity of data reporting effects of unilateral obstruction on contralateral testicular function in the AGR. This is despite works carried out on other animals like rabbit ${ }^{10}$ and monkeys ${ }^{11}$ amongst others. Antypas et al. ${ }^{1}$ showed that a bilateral deficiency in both Leydig and Sertoli cell secretory functions occurs in unilaterally vasectomized animals with an overall result of bilaterally impaired spermatogenesis and inhibited sperm maturation process. Previous studies by Saifzadeh and Derakhshanfar ${ }^{12}$ and Kong et al. ${ }^{13}$ utilized 12 native Sprague-Dawley rats and 19 Japanese rabbits in their investigations on unilateral vasectomy. Our present study focuses on the effects of unilateral vasectomy on testicular histology, testosterone and seminal parameters in the AGR.

\section{Methods}

\section{Animals}

Sixteen adult male African giant rats weighing between 500 and 1300grams were procured from Awolowo market in Mushin, Lagos and allowed to acclimatize in the Animal house of the Department

\section{Table 1: Experimental grouping of animals}

\begin{tabular}{lll}
\hline Groups & Treatment & Duration \\
\hline 1 & Unilateral vasectomy on right vas deferens & 8 weeks \\
2 & Unilateral vasectomy on right vas deferens & 6 weeks \\
3 & Unilateral vasectomy on right vas deferens & 2 weeks \\
4 & Sham-operated (control) & 8 weeks \\
\hline
\end{tabular}


( $\mathrm{H} \& \mathrm{E}$ ) before being viewed with an Olympus ${ }^{\circledR}$ binocular light microscope at magnifications X10 and X40.

Seminal fluid analysis included sperm motility, count and morphology. The caudal epididymis was excised and minced using a sterile scalpel blade before being placed in $0.5 \mathrm{ml}$ physiological saline $(0.85 \% \mathrm{NaCl})$ to allow the spermatozoa swim out freely. After two minutes of incubation, the solution was pipetted onto clean glass slides and cover-slipped for light microscopy at X40 magnification. Percentage of sperm motility was assessed using graded semi-quantitative scale of 0 to 5 and the spermatozoa were evaluated for the rate of forward movement and graded accordingly, WHO classification method i.e., $0=$ No movement, $1=$ Sluggish or tail movement alone, $2=$ Intermittent sluggish movement, 3-4 = Fair \& Good movement and $5=$ Maximum movement in forward direction ${ }^{16}$. Motility was defined as a sperm that showed any movement in the flagellum during a 30seconds observation period and was expressed as a percentage of motile sperm in total sperm ${ }^{17}$.

Sperm count was done using the improved counting chamber (Haemocytometer) and counting was done as described in Freund and $\mathrm{Carol}^{18}$. The spermatozoa count was obtained by counting the number of sperm cells in the four WBC chambers of the Neubauer's slide.

Sperm morphology: The fixed sperm were smeared on a glass slide and stained with phosphate buffered saline solution of Giemsa (Merck, Germany). Morphological alterations in spermatozoa head and flagellum were observed under 40X magnification as in Suresh et al. ${ }^{16}$.

\section{Testosterone assay}

Skin over the neck region was excised open immediately after anaesthesia and blood drawn from the common carotid artery using a $5 \mathrm{ml}$ syringe and needle. Blood sample was centrifuged at $3000 \mathrm{rpm}$ for 10 minutes using a bench centrifuge and the serum collected stored at $4^{\circ} \mathrm{C}$ before assay was carried out. The enzyme-linked immunoabsorbent assay (ELISA) technique (TECO Diagnostics, Anaheim, CA. Biotech Laboratory Ltd, UK) was used to assay for testosterone.

\section{Statistical analysis}

Data obtained were analyzed using the Student's ttest to compare variables and ANOVA with Turkeys post hoc test to compare between the groups and results expressed as mean $+\mathrm{SD} . \mathrm{P}<0.05$ was considered significant.

\section{Results \\ Mortality}

Only one rat died in group 1 after 6 weeks of treatment. Autopsy findings showed that death was due to trauma and respiratory pathologies.

Histopathology of testicular tissues: Testicular cross sections of left testis in control and all treated groups showed normal spermatogenic epithelium with 6 layered thickness of spermatogenic cells with small luminal diameter filled with immotile spermatozoa. There was severe seminiferous tubular atrophy with dense aggregation of inflammatory cells within the interstitium in the right testis of group 1 animals. Testicular sections in group 2 were essentially normal with slight reduction of spermatogenic layers to 4 in the right testis. In group 3, most of the right testis were atrophied with widely spaced tubules, few luminal spermatozoa and reduced spermatogenic layers. Figures 1 \& 2 represent low (x100) and high (x400) power magnifications for same slide. All sections were viewed by a Histopathologist and representative slide presented here for each group. Morphology: Spermatozoa recovered from control group and left testes of other experimental groups were normal in shape. They were no spermatozoa seen in group 1 (azoospermia) while those seen in group 3 had rounded head with short tail.

\section{Sperm count}

There was significant decrease in sperm count of right and left testes in groups 1-3 when compared with respective control. Though the sperm count in left testes were higher than the right testes, only group 3 values were significant $(\mathrm{p}<0.05)$ (table 2 ).

Spermatozoal motility: Significant declines in motility (more than $73 \%$ decrease) $(\mathrm{p}<0.05)$ were seen in groups 1 and 2 while group 3 was not significant (table 2).

\section{Testicular weight (TW)}

The right testes of groups 1,2 and 3 showed significant decline in TW when compared with those of control group of same side. However, there was a significant increase $(p<0.05)$ in TW between right and left testes of group 3 (table 2).

Testosterone assay: Though they were no significant difference in TT levels between other groups, the values for group 1 was significantly lower than control (table 2). 
Table 2: Testicular weight, seminal fluid analysis and testosterone assay for experiment groups

\begin{tabular}{|c|c|c|c|c|c|c|c|}
\hline \multirow[t]{2}{*}{ Group } & \multirow[t]{2}{*}{ Mean BW $(g)$} & \multirow[b]{2}{*}{ Right testis } & \multirow{2}{*}{$\begin{array}{l}\text { TW }(\mathrm{g}) \mathrm{BW}(\mathrm{kg}) \\
\text { Left testis }\end{array}$} & \multicolumn{2}{|c|}{ Sperm count $\left(\mathrm{x} 10^{6} / \mathrm{ml}\right)$} & \multirow[t]{2}{*}{ Motility (\%) } & \multirow[t]{2}{*}{ TT (ng/ml) } \\
\hline & & & & Right testis & Left testis & & \\
\hline 1 & $850 \pm 338$ & $1.57 \pm 1.11^{\alpha}$ & $2.26 \pm 1.6$ & $0.25 \pm 0.18^{\alpha}$ & $0.35 \pm 0.25^{\alpha}$ & $22.50 \pm 15.9^{\alpha}$ & $0.65 \pm 0.46^{\alpha}$ \\
\hline 2 & $850 \pm 273$ & $2.53 \pm 0.34^{\alpha}$ & $2.68 \pm 0.34$ & $0.15 \pm 0.74^{\alpha}$ & $0.18 \pm 1.13^{\alpha}$ & $19.00 \pm 9.00^{\alpha}$ & $1.33 \pm 0.14$ \\
\hline 3 & $795 \pm 226$ & $3.31 \pm 0.31^{\alpha}$ & $6.03 \pm 1.44^{\alpha}$ & $7.08 \pm 7.93^{\alpha}$ & $14.21 \pm 7.93^{\alpha}$ & $38.0 \pm 20.61$ & $1.40 \pm 0.20$ \\
\hline 4 & $847 \pm 204$ & $5.51 \pm 0.40$ & $5.35 \pm 0.24$ & $71.31 \pm 12.09$ & $50.00 \pm 1.56$ & $83.50 \pm 5.45$ & $1.33 \pm 0.14$ \\
\hline
\end{tabular}

Key: ${ }^{a} * \mathrm{p}<0.05$; TT is testosterone; BW represent mean is body weight; TW is testicular weight
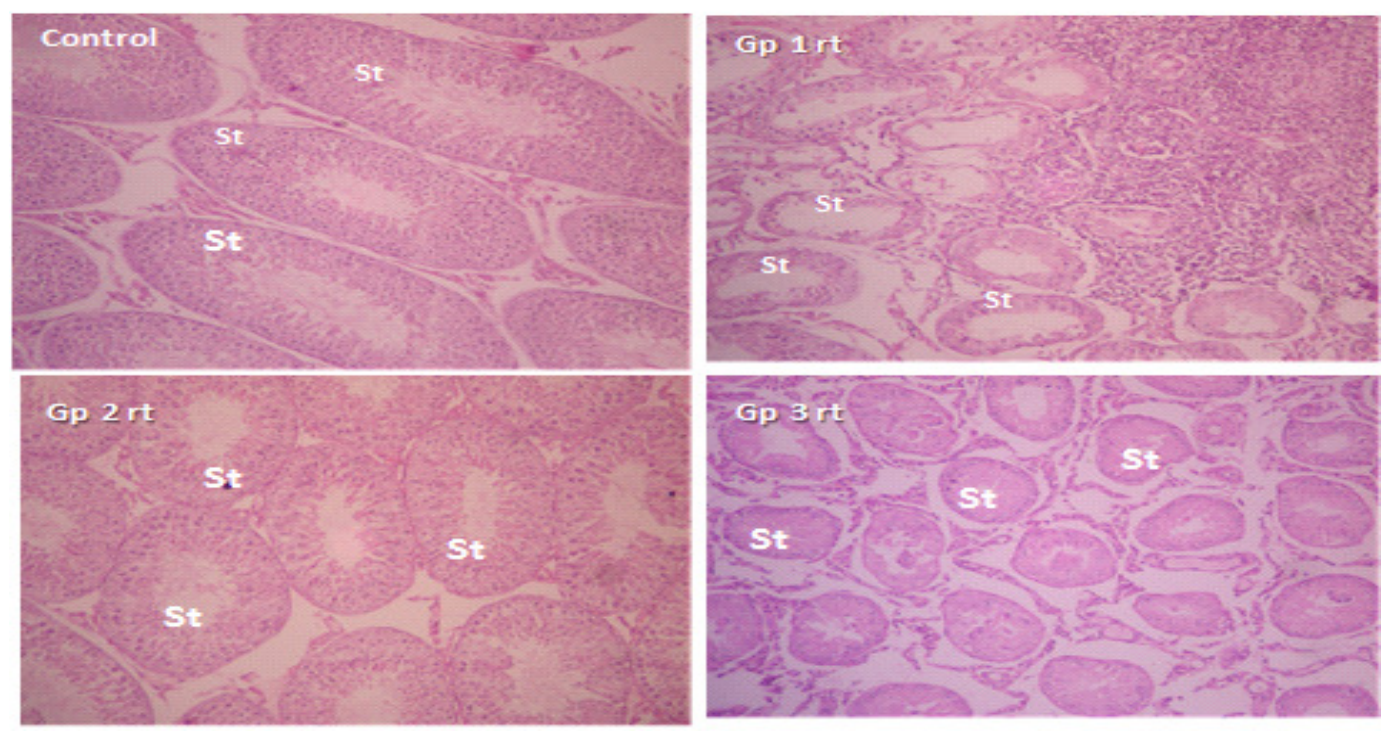

Figure 1: Testicular sections of right testis of control, right testis of groups 1, 2 and 3; H \& E x 100. St represent seminiferous tubules, note the marked atrophy of St in groups 1 and 3 respectively.
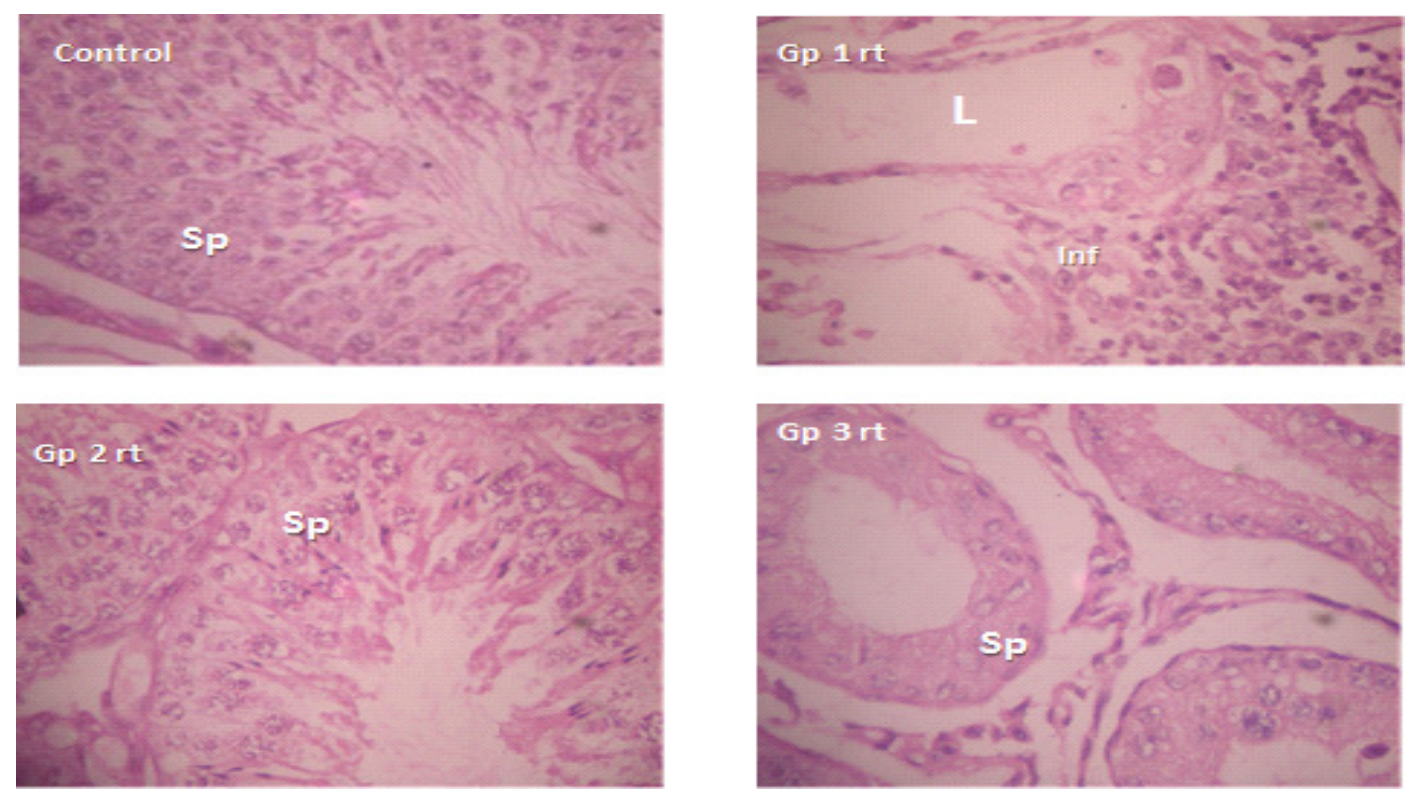

Figure 2: Testicular sections of right testis of control, right testis of groups 1, 2 and 3; $\mathrm{H} \mathrm{\&} \mathrm{E} \mathrm{x}$ 400. Sp represent spermatogenic cells in seminiferous tubules; $\mathrm{L}$ is lumen of seminiferous tubules; Inf is infiltrates in the interstittium; note extensive degeneration of spermatogenic cells in groups 1 and 3 respectively 


\section{Discussion}

While an intact vas deferens is a necessary anatomical structure for the conveyance of spermatozoa needed for procreation, vasectomy outcomes have been associated with various pathologies of the prostate gland although this remains a debated subject ${ }^{19}$. In humans, damage of the vas deferens during childhood often occurs as a complication of inguinal surgical operations such as inguinal herniorrhaphy ${ }^{20}$. The consequence of this has been noted and imbalance in sex hormones has been previously reported as a contributory factor responsible for pathological changes in the testis following vasectomy ${ }^{21}$. In our study, vasectomy in the AGR only resulted in a reduction in testosterone levels at 8 weeks indicating that this effect may likely be pronounced at longer duration.

Severe atrophy of seminiferous tubules observed in the histological sections of testicular tissues of vasectomized AGRs after 8 weeks mirrors the concomitant decline in testicular weight which could also be a direct effect of reduction in levels of testosterone hormone. This is corroborated by our previous studies which showed that decline in testosterone levels adversely affected seminiferous tubular morphologic and reproductive capacities of the testes of Sprague-Dawley rats ${ }^{22}$ which ultimately would compromise spermatozoal production. The reduction in TW in our result is proportional to the duration of vasectomy with the 8 weeks duration having the maximum decline. Also, it has been shown that smaller testicles after vasectomy showed severe alterations in the seminiferous tubules compared to heavier testicles that presented with normal morphology. As a result, the degree of morphologic changes corresponds closely to the testicular weight $\mathrm{t}^{23}$. However, part of the noted limitation of this preliminary work is the absence of stereologic data on seminiferous tubular morphology to actually quantify these observations. But we can infer that the gross perturbations seen in the atrophy of the seminiferous tubules more likely would negatively impact on the integrity of the spermatogenesis process in the testes.

In our result, we observed atrophy in the right testicular tissue; the reason for this remains to be investigated but we suggest that early alterations after vasectomy displayed histological changes which consisted mainly of depletion of germ cells. Again the extent of the depletion varied greatly in different seminiferous tubules and a possible role for humoral antibody in this model have been advocated by
Flickinger et al. ${ }^{24}$ since there is an association between testicular changes and serum antisperm antibodies.

The aggregation of inflammatory cells seen in testicular tissues of vasectomized AGRs is in tandem with the reports of Gupta et $a . .^{25}$ and may likely further lead to fibrotic changes in the testicular epithelium due to inflammation. A sperm granuloma is a complex network of multiple minimal epithelialized channels that help to prevent high intraluminal pressure in the obstructed ducts. Obstructive vasectomy induces a rise in pressure affecting the epididymis and efferent ductules. These structures become markedly distended and then adapt to reabsorb large volumes of testicular fluids and sperm products. Animal Studies show that epididymal and testicular obstruction due to vasectomy will eventually lead to rupturing of epididymal tubules and formation of granulomas in these animals ${ }^{20}$. However, data from our result shows that only testes of group 3 (left testicular weight) were significantly higher compared to the right testicular weight. But there was a significantly decreased TW of the ipsilateral testes in groups 1, 2 and 3 compared with the control which also mirrors similar pattern in hormonal aberrations. Antypas et al. ${ }^{1}$ have shown that a bilateral deficiency in both Leydig and Sertoli cell secretory functions occurs in unilaterally vasectomized animals with an overall result of bilaterally impaired spermatogenesis and inhibited sperm maturation process.

Declines in sperm count and motility observed in this study as well as other morphological aberrations seen in sperm morphology postvasectomy agrees with the works of Kim et al. ${ }^{26}$ and Blanco-Rodriguez and Martinez-Garcia ${ }^{27}$ that variations in circulating testosterone levels could adversely affect germ cell development. We reason that the defect in ipsilateral testicular function in the AGR testis with obstructed right vas deferens can be easily explained as it corroborates the work of Lamano-Carvalho et al. ${ }^{6}$. The high pressure within the epididymal and seminiferous tubules due to the obstruction leads to extension and dilation of the tubules and the exit of spermatozoa from epididymal and seminiferous tubules. This may result in interstitial fibrosis of the testes and secondary epididymal obstruction ${ }^{20}$.

The reason why biochemical test results (testosterone assay) could not reach the level of statistical significance in other groups (except group 1) unlike histological observations remains to be understood. However, we aver that the longer duration of 
animals in group 1 might be responsible for this observation but this certainly will be confirmed if a larger cohort of AGR is recruited for more elaborate study. But our preliminary conclusion from the results shown indicates that ipsilateral vasectomy does alter the contralateral testicular parameters in the AGR in the short duration. Further work is advocated on these observations in view of the increasing domestication of the African giant rat and a possible 'humanization' effects.

\section{Conclusion}

While studies to elucidate changes in the male reproductive organs following vasectomy procedures in the African giant rat is limited, we have highlighted in our study that unilateral vasectomy may disrupt testicular parameters that would eventually compromise the integrity of the seminiferous tubular function.

\section{References}

1. Antypas S, Sofikitis N, Rodriguez F, Zavos PM, Miyagawa I. Bilateral effect of unilateral vasectomy on testicular testosterone biosynthesis. Journal of Pediatric Surgery. 1994; 26:828-831.

2. Handelsman D and Waites G. Traditional methods. In: Schill W, Comhaive F, Hargreave $\mathrm{T}$ (eds). Andrology for the Clinician. Berlin: Springer Verlag. 2006; 122-124.

3. Basimoglu KY, Onarlioglu B, Bulut HE and Gunay Y. comparison of the effects of vasectomy and experimental cryptorchidism in rats: II. Epididymal histology. Okajimas Folia Anatomica Jpn, 1998; 75(5): 217-223.

4. Miller RJ, Killian GJ and Vasilenko P III. Effects of long and short-term vasectomy on structural and functional parameters of the rat. Journal of Andrology. 1984; 5: 381-388.

5. Neaves WB (1975). Biological aspects of vasectomy. In: Greep RO, Astwood EB, eds. Handbook of physiology. Section 7. Male reproductive system. Baltimore: Williams and Wilkins; p. 383-404.

6. Lamano-Carvalho TL, Favaretto AL, AntunesRodrigues J. Histopathological study of vasectomized rats. Brazilian Journal of Medical and Biological Research. 1984; 17: 83-91.

7. Alexander NJ, Free MJ, Paulsen CA, Buschbom R, Fulgham DL. A comparison of blood chemistry, reproductive hormones and the development of anti-sperm antibodies after vasectomy in men. Journal of Andrology. 1980; 1 : 40-50.

8. Whyte J, Sarrat R., Cisneros AI, Whyte A, Mazo $\mathrm{R}$, Torres A, Lazaro J. The vasectomized testis. International Surgery. 2000; 85, 167-174.

9. Olude MA, Olopade JO. Morphometric Studies of the Axial Skeleton of the African Giant Rat (Cricetomys gambianus, Waterhouse) Part (1): Skull Typology Anat. Journal of Veterinary Anatomy. 2010; 3(2): 1 - 12.

10. Alexander NJ, Tung KSK. Immunological and morphological effects of vasectomy in the rabbit. Anatomical Record. 1997; 188: 339-350.

11. Peng B, Zhang RD, Dai XS, Deng XZ, Wan Y, Yang ZW. Quantitative (stereological) study of the effects of vasectomy on spermatogenesis in rhesus monkeys (Macaca mulatta). Reproduction. 2002; 124: 847-856.

12. Saifzadeh $\mathrm{S}$ and Derakhshanfar A. the effects of experimental unilateral vasectomy on testicular structure in the rat. Iranian Journal of Veterinary Research. 2004; 5(2): 1383.

13. Kong L, Huang A, Deng X and Yang Z. Quantitative (stereological) study of the effects of vasectomy on spermatogenesis in rabbits. Journal of Anatomy. 2004; 205:147-156.

14. Ajayi SS. Live and carcass weights of giant rat (Cricetomys gambianus, Waterhouse) and domestic rabbit (Oryctolagus cuniculusL). African Journaal of Ecololgy. 1977; 15: 223-227.

15. Cooper RG. Care, husbandary and diseases of the African giant rat (Cricetomys gambianus). Journal of the South African Veterinary Association. 2008; 79(2): 62-66.

16. Suresh S, Shanthi Santhosh Kumari S, Preethi U, Venkatalakshmi N, Karthik Ganesh M, Ganesh L, Prithiviraj E, Prakash S. Long-Term Hyperglycemic effect on rat Epididymis and Sperm. International Journal of Anatomical Sciences. 2011; 2(1):11-17.

17. Yokoi K, Uthus EO, Nielsen FH. Nickel deficiency diminishes sperm quantity and movement in rats. Biology Trace Element Research. 2003; 93: 141-153.

18. Freund M, Carol B. Factors affecting haemocytometer counts of sperm concentration in human semen. Journal of Reproduction and Fertility. 1964; 8: 149-15.

19. Pereira S, Martinez M, Martinez FE, Mello Junior W. Repercussions of castration and vasectomy on the ductal system of the rat ventral prostate. Cell Biology International. 2006; 30: 169-174.

African Health Sciences Vol 13 Issue 2 June 2013 
20. Ikeda T, Sofikitis N. Bilateral testicular consequences in the unilateral vasectomy of immature rats. Yonago Acta Medica. 2000; 43: 1-9.

21. Geierhaas B, Bornstein SR, Jarry H, Scherbaum WA, Herrmann M, Pfeiffer EF. Morphological and hormonal changes following vasectomy in rats, suggesting a role for Leydig cell associated macrophages. Hormone and Metabolism Research. 1991; 23: 373-378.

22. Azu OO, Duru FIO, Osinubi AA, Oremosu AA, Noronha CC, Elesha SO, Okanlawon AO. Histomorphometric effects of Kigelia africana (Bignoniaceae) fruit extract following short-term treatment with cisplatin in male SpragueDawley rats. Middle East Fertility Society Journal (MEFSJ). 2010; 15: 200-208.

23. Flickinger C J, Herr JC, Howards SS, Caloras D, Scott Yarbro E, Spell DR, Gallien TN . The influence of vasovasostomy on testicular alterations after vasectomy in Lewis rats. The Anatomical Record. 1987; 217: 137-145.
24. Flickinger CJ, John C. Herr, Stuart S. Howards, John R. Sisak, Janice M. Gleavy, et al. Testicular alterations were not reversed by performance of a vasovasostomy 1 month after vasectomy. The Anatomical Record. 1990; 227(1): 37-46.

25. Gupta A, Kothari A, Dhrura A, Bapna R. Surgical sterilization by vasectomy and its effect on the structure and function of the testis in man. British Journal of Surgery. 1975; 62: 52-63.

26. Kim JM, Ghosh SR, Weil ACP, Zirkin BR. Caspase-3 and caspase-activated dioxyribonuclease are associated with testicular germ cell apoptosis resulting from reduced intratesticular testosterone. Endocrinology. 2001; 142: 3809-3816.

27. Blanco-Rodriguez J, Martinez-Garcia C. Apoptosis precedes detachment of germ cells from the seminiferous epithelium after hormonal suppression by short-term estradiol treatment of rats. International Journal of Andrology. 1998; 21: 109-115. 